\title{
Temperature ranges for survival and growth of juvenile Saccharina sculpera (Laminariales, Phaeophyta) and applications for field cultivation
}

\author{
Soo Hong Kim, Young Dae Kim, Mi Sook Hwang, Eun Kyoung Hwang and Hyun Il Yoo* \\ Fisheries Seed and Breeding Research Institute, National Institute of Fisheries Science, Haenam 59002, Korea
}

Saccharina sculpera is highly valued for human consumption and value-added products. However, natural resources of this kelp have decreased sharply and it is in danger of extinction. Resources recovery through cultivation is being trialed to enable the sustainable use of this species. In this study, the temperature range for survival and optimal growth of juvenile $S$. sculpera was identified and applied to field cultivation. This study investigated the survival and growth of juvenile S. sculpera under six temperatures (i.e., 5, 10, 15, 16, 18, and $20^{\circ} \mathrm{C}$ ) and two light intensities (i.e., 20 and 40 $\mu \mathrm{mol}$ photons $\left.\mathrm{m}^{-2} \mathrm{~s}^{-1}\right)$ in an indoor culture experiment. In these experiments, the blade length decreased at $16^{\circ} \mathrm{C}$ under the both light intensities. The thalli died at $20^{\circ} \mathrm{C}$ and $20 \mu \mathrm{mol}$ photons $\mathrm{m}^{-2} \mathrm{~s}^{-1}$, and at $18-20^{\circ} \mathrm{C}$ and $40 \mu \mathrm{mol}$ photons $\mathrm{m}^{-2}$ $\mathrm{s}^{-1}$. During the field cultivation, early growth of $S$. sculpera was highest at the $5 \mathrm{~m}$ depth and growth decreased as the water depth increased. When the initial rearing depth was maintained without adjustment throughout the cultivation period (from December to October), all the cultivated S. sculpera plants died during August and September. However, $S$. sculpera plants lowered from 5 to $15 \mathrm{~m}$ and grew to $90.8 \pm 13.1 \mathrm{~cm}$ in July. The seawater temperature at $15 \mathrm{~m}$ depth was similar to the upper level of thermal tolerance demonstrated by juvenile S. sculpera in the indoor culture experiments $\left(16^{\circ} \mathrm{C}\right.$ or lower). The plants were subsequently lowered to $25 \mathrm{~m}$ depth in August, which eventually led to their maturation in October. The present study confirmed that improved growth rates and a delay in biomass loss can be achieved by adjusting the depth at which the seaweeds are grown during the cultivation period. These results will contribute to the establishment of sustainable cultivation systems for S. sculpera.

Key Words: cultivation; light intensity; Saccharina sculpera; temperature; water depth

\section{INTRODUCTION}

Saccharina sculpera (Miyabe), Lane, Mayes, Druehl and Saunders, is a brown alga belonging to the Order Laminariales, Class Phaeophyceae (Kang 1968, Boo et al. 2010), which is distributed in the coast of Gangneung, Gangwon Province, Korea, in Hokkaido Island, Japan, and in the southern region of Sakhalin, Russia (Lee and Kim 1999, Ozaki et al. 2001, Kim 2003, Galanin et al. 2011).
In general, brown algae are rich in water-soluble polysaccharides such as fucoidan and alginic acid. The fucoidan derived from S. sculpera exhibits more diverse biological properties than those obtained from other related species such as Costaria costata, Saccharina japonica, and Undaria pinnatifida (Qu et al. 2019, Ren et al. 2019). This alga is widely used in various industries as ingredi-
(1) \$ This is an Open Access article distributed under the terms of the Creative Commons Attribution Non-Commercial License (http://creativecommons.org/licenses/by-nc/3.0/) which permits unrestricted non-commercial use, distribution, and reproduction in any medium, provided the original work is properly cited.
Received July 7, 2021, Accepted November 21, 2021

*Corresponding Author

E-mail: hiyoo@korea.kr

Tel: +82-61-530-3906, Fax: +82-61-532-5806 
ents in functional foods, nutraceuticals, and cosmetics (Sakai and Kato 2001, 2002, Qu et al. 2019, Leandro et al. 2020). In Hakodate, Hokkaido, Japan, the production of S. sculpera has been decreasing since late 1990s due to the loss of wild S. sculpera beds caused by increased water temperatures, summer typhoons, and marine pollution (Takahashi 2000). The eastern coast of Gangwon Province, Korea, particularly Gangneung, had the largest S. sculpera population, covering over 50 ha and providing an annual production of around 1,000 tons (wet wt) in the 1990s. However, due to overexploitation of the natural resource and changes in the coastal environment, the yield declined (Kim 2003, Kim et al. 2005), and S. sculpera has not been observed in this area since 2010 .

Previous studies on S. sculpera include the monthly variation in the occurrence and growth of the seaweed in the coast of Hokkaido, Japan (Yamamoto 1986), the effect of temperature and light intensity on their callus formation and tissue differentiation (Notoya and Kim 1996), uptake of nutrients (Ozaki et al. 2001), and extraction of functional bioactives (fucoidan) (Katayama et al. 2009). Recently, a study has been conducted on the phenology and morphology of natural S. sculpera populations from Hokkaido, Japan to aid with the restoration and conservation of this species (Tani et al. 2015). In Korea, research on S. sculpera have been confined to the environmental adaptation of this native kelp in the Gangwon coast (Kim 2003), identification of the optimal growth conditions of gametophytes and sporophytes through indoor culture (Kim et al. 2005), as well as the isolation and preservation of male and female gametophytes and early growth characteristics (Kim et al. 2007a, 2007b). The only previous research conducted for the purpose of aquaculture was a study on the optimal conditions for S. sculpera seedling production which utilized male and female gametophytes separated and preserved by the National Institute of Fisheries Science (Yoo et al. 2018).

The growth, maturity, and distribution of seaweeds are affected by biological and physicochemical conditions such as light, water temperature, nutrients, tides, and competition (South and Whittick 1987). Light and temperature are the primary limiting factors in the growth and maturity of algae, and they determine the horizontal and vertical distributions (Breeman 1988, Lüning 1993). These environmental factors also control the production of cultivated seaweeds (Hwang and Park 2020, Ko et al. 2020). With the declining wild populations of S. sculpera, it is necessary to develop cultivation techniques for this species. This study aimed to determine the temperature range for survival and optimum growth of juvenile $S$. sculpera in the laboratory, and to determine the optimal water depth and temperature combinations for growth and maturity of this species in the sea.

\section{MATERIALS AND METHODS}

\section{Collection and culture of gametophytes}

Male and female gametophytes (SRI-P00143 ${ }^{\circ}, 00144{ }^{3}$ ) of S. sculpera were obtained from the Fisheries Seed and Breeding Research Institute, National Institute of Fisheries Science, Korea. The gametophyte $(\geq \emptyset 1 \mathrm{~mm}$ ) stocks were separately placed in $200 \mathrm{~mL}$ beakers with $100 \mathrm{~mL}$ of sterilized sea water, and were fractionated into around $100 \mu \mathrm{m}$ in size using a homogenizer (DI 25basic; GMBH \& Co., Staufen, Germany). The fractionated male and female gametophytes were mixed at a ratio of $2: 1$, and were placed in a $1 \mathrm{~L}$ beaker with PESI medium (Tatewaki 1966) and seed strings (200 pieces, 5-6 cm long) for gametophyte fertilization and attachment (Hwang et al. 2015). Gametophyte cultures were maintained at $15^{\circ} \mathrm{C}$ under $40 \mu \mathrm{mol}$ photons $\mathrm{m}^{-2} \mathrm{~s}^{-1}$ (14:10 h light : dark cycle) for 10 weeks, until the development into $\geq 5 \mathrm{~mm}$ juvenile sporophytes (Yoo et al. 2018). Culture medium was renewed every seven days.

\section{Juvenile sporophyte growth under different light intensity and temperature}

To determine the effects of temperature on the survival and growth of the juvenile S. sculpera, the juvenile sporophytes ( $\sim 6 \mathrm{~mm}$ in size) were removed from the seed string. Five of the selected thalli were placed into a Petri dish $(\varnothing 6 \mathrm{~cm})$ with PESI culture medium $(10 \mathrm{~mL})$ and were cultured for 21 days under various temperatures (5, $10,15,16,18$, and $\left.20^{\circ} \mathrm{C}\right)$ and light intensity conditions (20 and $40 \mu \mathrm{mol}$ photons $\mathrm{m}^{2} \mathrm{~s}^{-1}$ ). There were three replicates for each treatment, and the photoperiod during the incubation was fixed at $14: 10 \mathrm{~h}(\mathrm{~L}: \mathrm{D})$. The National Institute of Fisheries Science (2020) reported that the juveniles died at temperatures above $20^{\circ} \mathrm{C}$, but the experimental temperatures for that trial had been set at $5^{\circ} \mathrm{C}$ intervals, which limited the accuracy of identifying the critical temperature for survival of the juvenile stage. Therefore, the temperature conditions in the present study was set at $2^{\circ} \mathrm{C}$ intervals from $16^{\circ} \mathrm{C}$ to provide a more accurate estimate of the upper lethal temperature for juvenile sporophytes. The blade length of $S$. sculpera was measured 2, 5 , and 7 days after the start of culture, and every 7 days 


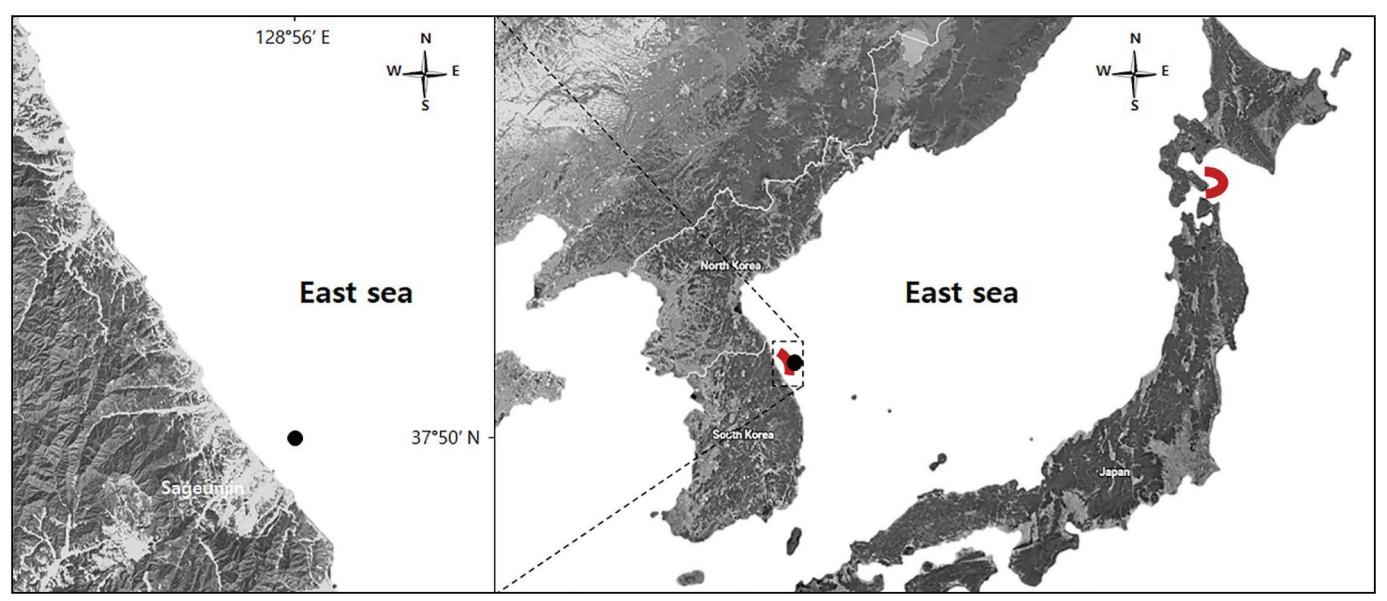

Fig. 1. A map showing the natural habitat and cultivation sites of Saccharina sculpera in Korea and Japan. The red lines represent the natural habitat of S. sculpera (both historically and in the present day), and the black dot marks the field cultivation site of S. sculpera.

thereafter. Renewal of culture medium was done every 7 days. The relative growth rate (RGR) of S. sculpera was calculated using the following equation (Serisawa et al. 2002):

$$
\operatorname{RGR}\left(\% \mathrm{~d}^{-1}\right)=\left[\ln \left(\mathrm{L}_{2}\right)-\ln \left(\mathrm{L}_{1}\right)\right] /\left(\mathrm{T}_{2}-\mathrm{T}_{1}\right) \times 100
$$

, where $\mathrm{L}_{1}$ and $\mathrm{L}_{2}$ are the sporophyte blade lengths at $\mathrm{T}_{1}$ and $\mathrm{T}_{2}$ in days, respectively.

\section{Field cultivation}

The field experiments were carried out in the open waters off the Sageunjin coast of Gangneung, Gangwon Province, Korea, where natural populations of S. sculpera had grown abundantly at depths of 20-30 m (Fig. 1). The seed strings (Fig. 2A) were inserted into a $\emptyset 3 \mathrm{~mm}$ transplant rope, which were then wound around the cultivation rope (Ø $40 \mathrm{~mm}$ ) (Fig. 2B). Cultivation ropes with juveniles of $S$. sculpera were hanged vertically from hanging long-lines at a range of depths (5-25 m) on Dec 19, 2019 (Fig. 2C). The length of the cultivation ropes was adjusted in order to provide the desired depths (5-25 m) (Fig. $3)$. Five cultivation ropes were deployed at each depth treatment. The blade length and maturity of S. sculpera treatments were determined by randomly collecting 20 individuals every month from December 2019 to October 2020. Water temperature profiles were recorded during monthly growth measurements. When the water temperature rose to $16^{\circ} \mathrm{C}$ or above, the rearing depth was adjusted to a depth $(5,10 \mathrm{~m} \rightarrow 15 \mathrm{~m}$ in June, $15 \mathrm{~m} \rightarrow 25 \mathrm{~m}$ in August) where the water temperature was below $16^{\circ} \mathrm{C}$. Culture depths were adjusted in three of the five cultiva- tion ropes, while the initial depth was maintained in two cultivation ropes.

\section{Monitoring of environmental parameters}

The water temperature at each treatment depth was measured using a multi-parameter water quality meter (YSI proDSS; YSI Inc., Yellow Springs, OH, USA). The light intensity at each depth was measured using an LI-193SA (with LI-1400; LI-Cor, Lincoln, NE, USA) underwater quantum sensor in February and July. The probe was held at each depth for $5 \mathrm{~min}$ and measurements were taken 5 times at 1-min intervals and the average was calculated.

\section{Statistical analysis}

Statistical analysis of the temperature and light effects on juvenile S. sculpera was performed by a two-way ANOVA, and if there were significant differences, postvalidation was conducted using the Tukey's test method. The statistical analyses were performed using STATISTICA version 6.0 (Statsoft, Tulsa, OK, USA).

\section{RESULTS}

\section{Growth of Saccharina sculpera juveniles at differ- ent temperatures and light intensities}

Juvenile S. sculpera were cultured at different temperatures $\left(5,10,15,16,18\right.$, and $\left.20^{\circ} \mathrm{C}\right)$ and light intensities $(20$ and $40 \mu \mathrm{mol}$ photons $\mathrm{m}^{-2} \mathrm{~s}^{-1}$ ) in order to determine their optimum growth conditions. After 21 days of incuba- 


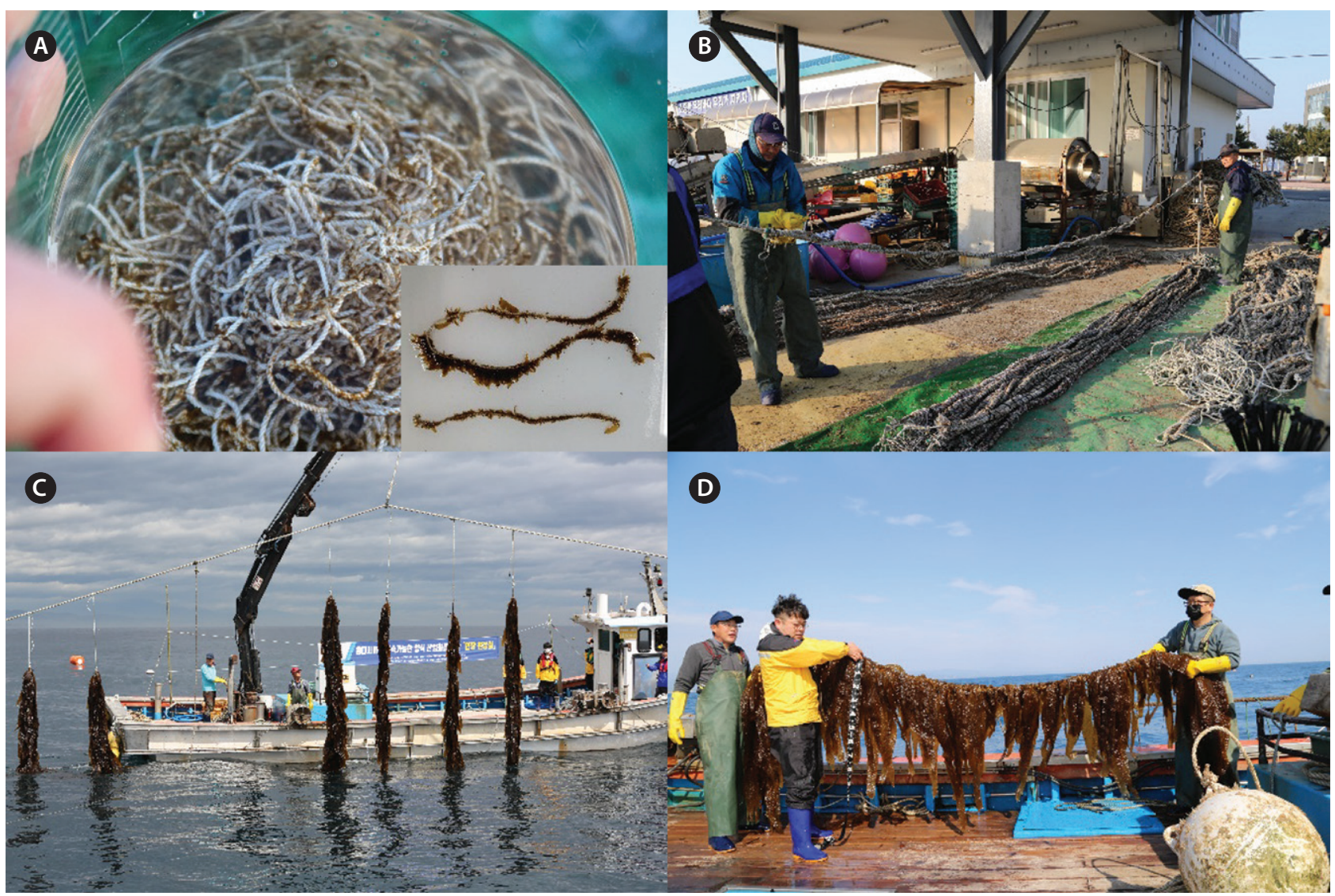

Fig. 2. Procedure for field cultivation of Saccharina sculpera. (A) Young blades on seed strings after 10 weeks culture in situ. (B) Seed strings with juveniles were inserted into transplant rope $(\varnothing 3 \mathrm{~mm}$ ), which were subsequently wound around the cultivation rope (Ø $40 \mathrm{~mm})$. (C) Cultivation ropes were hanged vertically from hanging-long lines at a range of depths ( $5-25 \mathrm{~m})$. (D) S. sculpera thalli after 5 months of grow-out.

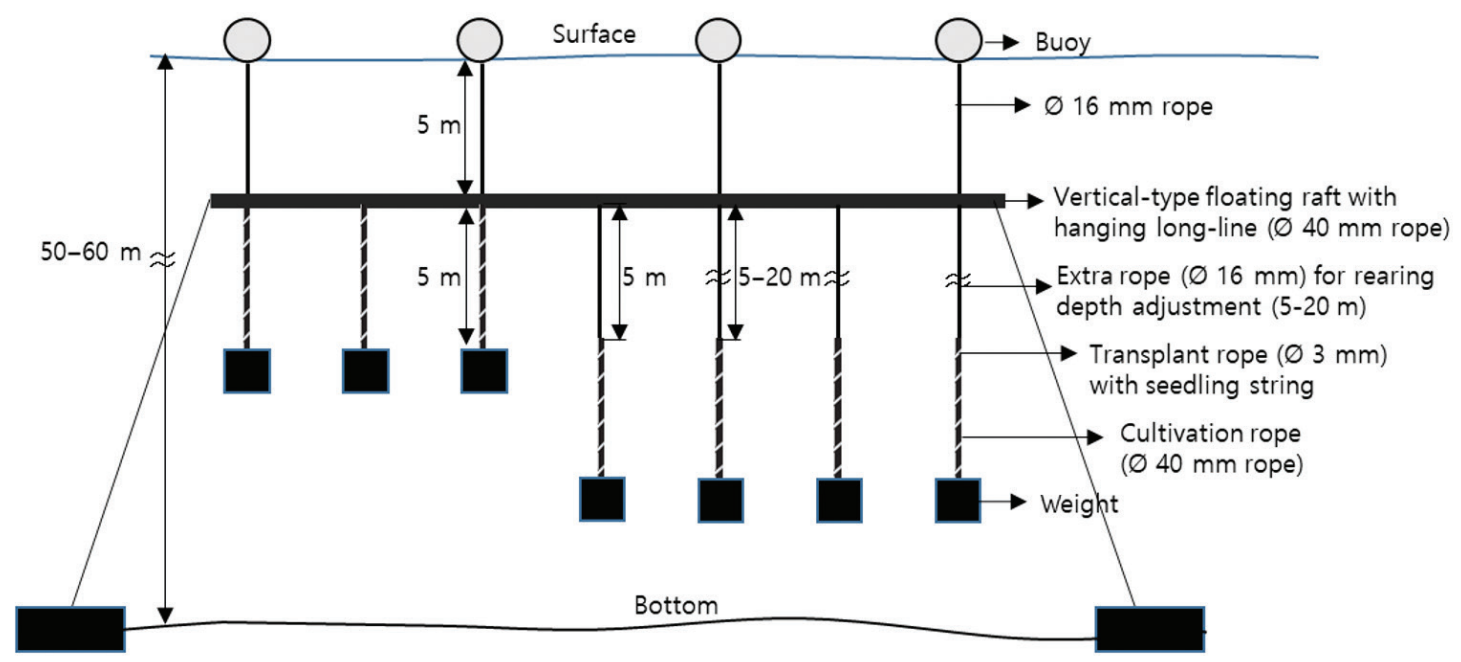

Fig. 3. Design of field cultivation experiment to allow trials at different depths. 

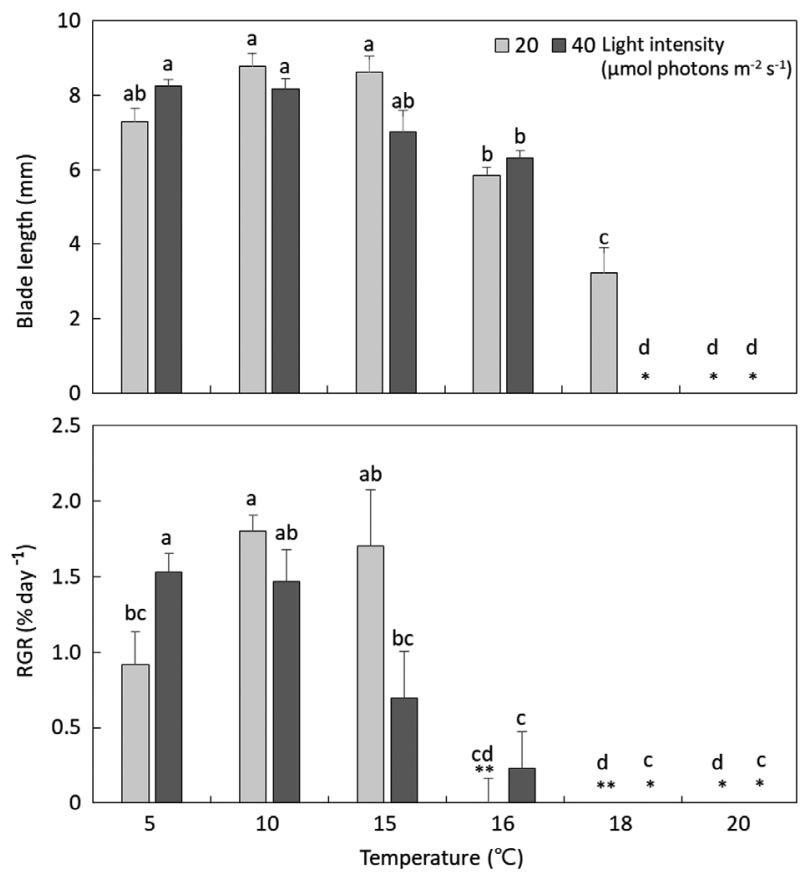

Fig. 4. Blade length and relative growth rates (RGR) of juvenile Saccharina sculpera sporophytes after 21 days in relation to temperature and light intensity conditions. The asterisk $(*)$ and double asterisk ${ }^{* *}$ ) mean the death of sporophytes and length reduction due to biomass loss, respectively. Bars are standard errors ( $\mathrm{n}=3$ replicates). Mean with different letters are significantly different (Tukey's honestly significant difference, $\mathrm{p}<0.01$ ).

tion, the maximum blade length $(8.77 \pm 0.36 \mathrm{~mm}$, mean $\pm \mathrm{SE}$ ) was achieved at $20 \mu \mathrm{mol}$ photons $\mathrm{m}^{-2} \mathrm{~s}^{-1}$ and $10^{\circ} \mathrm{C}$. The largest blade length at $40 \mu \mathrm{mol}$ photons $\mathrm{m}^{-2} \mathrm{~s}^{-1}$ was observed at $5^{\circ} \mathrm{C}$. There was no significant difference in the blade length of the juvenile $S$. sculpera in the $5-15^{\circ} \mathrm{C}$ range at the two light intensity conditions (Fig. 4), but the average blade length decreased at temperatures above $16^{\circ} \mathrm{C}$ (Fig. 5). No growth occurred at $18-20^{\circ} \mathrm{C}$ under 20 and $40 \mu \mathrm{mol}$ photons $\mathrm{m}^{-2} \mathrm{~s}^{-1}$ (Fig. 5). This confirmed that the blade length were significantly affected by both temperature and irradiance (Table 1).

The RGR of juvenile S. sculpera after 21 days of culture at different temperatures and light intensities are shown
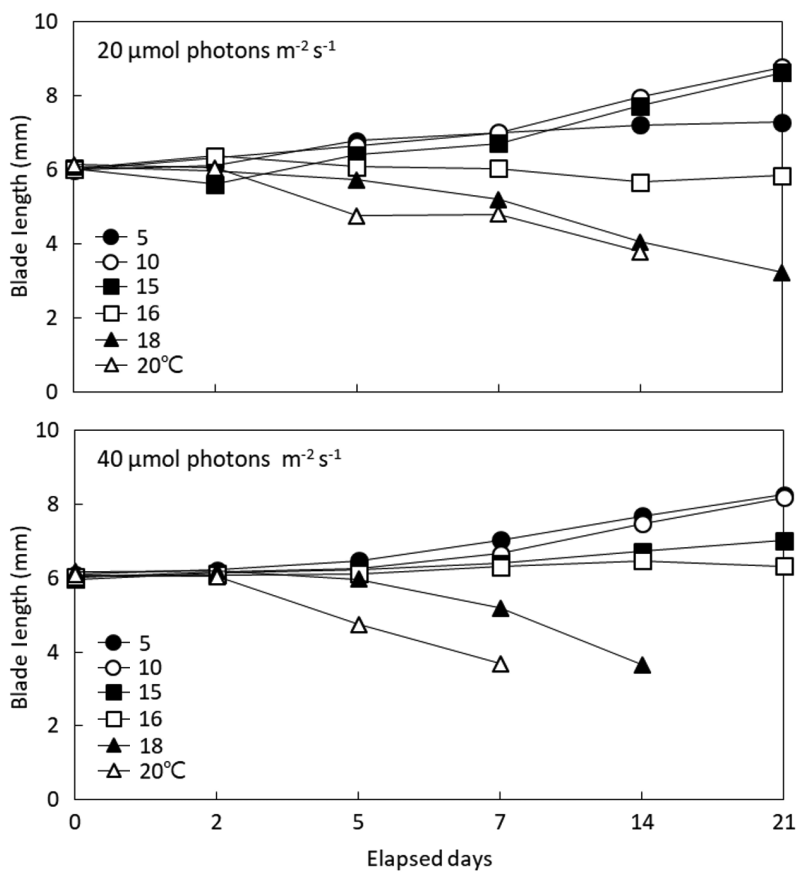

Fig. 5. Effects of temperature and light intensity on growth of juvenile Saccharina sculpera sporophytes with photoperiod of $14: 10 \mathrm{~h}$ light : dark cycle.

in Fig. 4. At $20 \mu \mathrm{mol}$ photons $\mathrm{m}^{-2} \mathrm{~s}^{-1}$, the growth ranged from -3.21 to $1.80 \% \mathrm{~d}^{-1}$ with the largest growth achieved at $10^{\circ} \mathrm{C}\left(1.80 \pm 0.11 \% \mathrm{~d}^{-1}\right)$. The RGR decreased at $16^{\circ} \mathrm{C}$ $\left(-0.14 \pm 0.31 \% \mathrm{~d}^{-1}\right)$ and $18^{\circ} \mathrm{C}\left(-3.21 \pm 0.82 \% \mathrm{~d}^{-1}\right)$, and no growth occurred at $20^{\circ} \mathrm{C}$; the seaweeds eventually died at the end of culture period. At $40 \mu \mathrm{mol}$ photons $\mathrm{m}^{-2} \mathrm{~s}^{-1}$, the highest RGR was obtained at $5^{\circ} \mathrm{C}\left(1.53 \pm 0.13 \% \mathrm{~d}^{-1}\right)$, the RGR decreased with rise in water temperature, with biomass loss above $16^{\circ} \mathrm{C}$.

\section{Saccharina sculpera cultivation environment measurements}

The surface water temperatures measured during the monthly survey of $S$. sculpera were lowest at $10.6^{\circ} \mathrm{C}$ in February, then gradually increased until they peaked at

Table 1. Results of two-way ANOVA and Tukey's tests for the effects of light intensity and temperature on blade length and relative growth rates (RGR) of juvenile Saccharina sculpera sporophytes after 21 days in indoor culture

\begin{tabular}{|c|c|c|c|c|c|c|c|c|}
\hline \multirow{2}{*}{ Factor } & \multicolumn{4}{|c|}{ Blade length } & \multicolumn{4}{|c|}{ RGR } \\
\hline & df & MS & $F$ & p-value & df & MS & $\mathrm{F}$ & p-value \\
\hline Light intensity ( $\mu \mathrm{mol}$ photons $\mathrm{m}^{-2} \mathrm{~s}^{-1}$ ) & 1 & 3.95 & 11.08 & $<0.01$ & 1 & 0.06 & 0.73 & $>0.05$ \\
\hline Temperature $\left({ }^{\circ} \mathrm{C}\right)$ & 5 & 77.87 & 218.31 & $<0.01$ & 5 & 3.14 & 33.10 & $<0.01$ \\
\hline Interaction & 5 & 3.44 & 9.96 & $<0.01$ & 5 & 0.45 & 4.70 & $<0.01$ \\
\hline Error & 24 & 0.36 & & & 24 & 0.09 & & \\
\hline
\end{tabular}




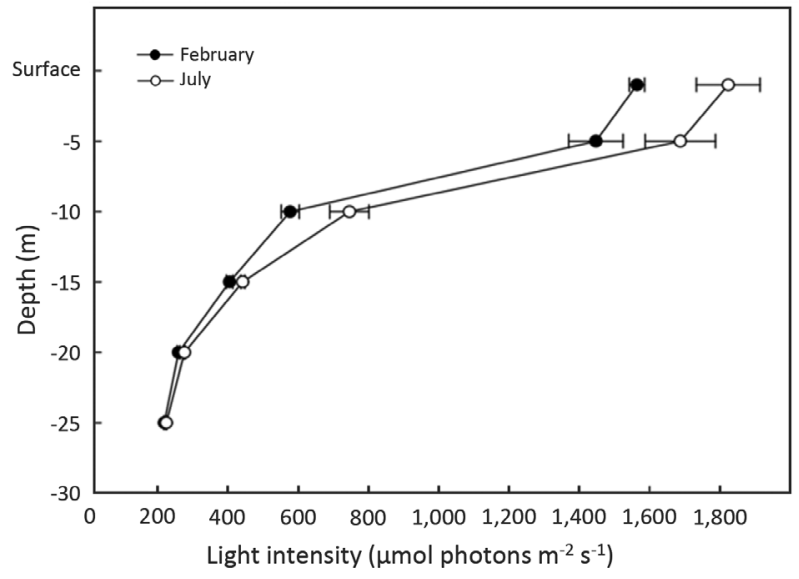

Fig. 6. Vertical profiles of light intensity in February and July. Bars are standard deviation $(n=5)$.

$21.6^{\circ} \mathrm{C}$ in August and gradually dropped thereafter. No apparent thermocline was observed from December to March, with a variation in water temperature of between $0-0.4^{\circ} \mathrm{C}$ from the surface to $25 \mathrm{~m}$ depth. A thermocline was observed at $15 \mathrm{~m}$ depth in June and $25 \mathrm{~m}$ depth in July and August (Table 2).

The light intensity measured during the field survey in February and July decreased sharply as the water depth increased; the light intensity measured in February was lower than that measured in July. With increasing depth the difference in light intensity reduced between the two months. The light intensity at $25 \mathrm{~m}$ was close to $20 \mu \mathrm{mol}$ photons $\mathrm{m}^{-2} \mathrm{~s}^{-1}$ in both months (Fig. 6).

\section{Growth and maturity of the cultured population}

To determine the optimum rearing depth, S. sculpera was cultivated at a range of depths $(5,10,15,20,25 \mathrm{~m})$. Kelp sporophytes cultured at $5 \mathrm{~m}$ depth had a mean

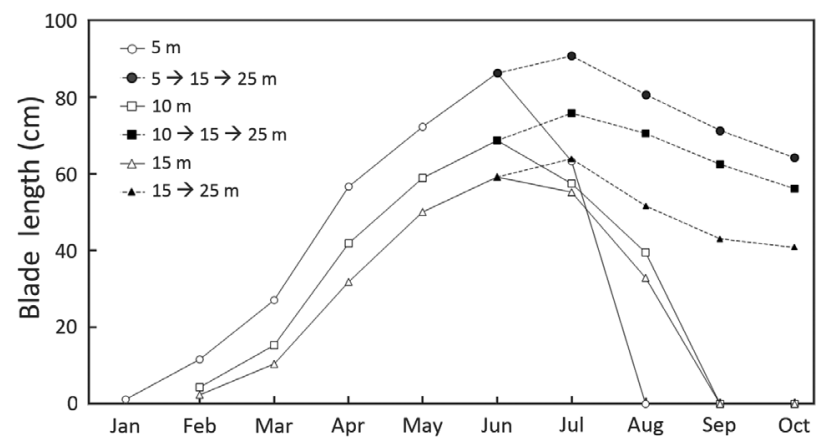

Fig. 7. Monthly changes of blade length of Saccharina sculpera in relation to depth. Kelp sporophytes were cultured at a range of depths (5-25 m) from December 2019 to October 2020. Cultivation ropes were adjusted from 5 and $10 \mathrm{~m}$ to $15 \mathrm{~m}$ in June and from 15 to $25 \mathrm{~m}$ in August 2020.

blade length of $1.1 \pm 0.2 \mathrm{~cm}$ in January, a month after the start of rearing; they continued to grow until June when the blade length peaked at $86.3 \pm 12.4 \mathrm{~cm}$. The sporophytes subsequently showed a decrease in blade length $(63.2 \pm 14.6 \mathrm{~cm})$ in July, until they disappear by the end of August (Fig. 7). As for kelp seedlings cultured at 10 and $15 \mathrm{~m}$, young sporophytes were first observed in February with lengths of $4.3 \pm 0.56$ and $2.3 \pm 0.47 \mathrm{~cm}$, respectively. In June, the blade lengths peaked at $68.7 \pm 15.21$ and 59.1 $\pm 13.9 \mathrm{~cm}$, respectively, and decreased thereafter until none remained in September. On one hand, the experimental groups that were lowered from 5 to $15 \mathrm{~m}, 10$ to $15 \mathrm{~m}$, and 15 to $25 \mathrm{~m}$ in June grew further in July as their blade lengths peaked at $90.8 \pm 13.1,75.8 \pm 12.8$, and 63.9 $\pm 13.7 \mathrm{~cm}$, respectively. Experimental cultures that had been lowered to $15 \mathrm{~m}$ depth were subsequently reared at deeper depth of $25 \mathrm{~m}$ in August, and yet their blade lengths decreased (Fig. 7). A comparison of blade length with rearing depth in June showed that the blade lengths

Table 2. Temperature according to water depth in the cultivation area of Saccharina sculpera

\begin{tabular}{cccccccccccc}
\hline \multirow{2}{*}{ Depth $(\mathbf{m})$} & \multicolumn{10}{c}{ Temperature $\left({ }^{\circ} \mathbf{C}\right)$} \\
\cline { 2 - 12 } & Dec & Jan & Feb & Mar & Apr & May & Jun & Jul & Aug & Sep & Oct \\
\hline 1 & 15.0 & 13.1 & 10.6 & 12.0 & $*$ & $*$ & 21.5 & 20.6 & 21.6 & 21.0 & 17.9 \\
5 & 15.0 & 13.1 & 10.6 & 11.9 & $*$ & $*$ & 20.9 & 19.4 & 20.1 & 20.4 & 17.8 \\
10 & 15.0 & 13.1 & 10.6 & 11.9 & $*$ & $*$ & 19.0 & 18.9 & 19.5 & 20.1 & 17.3 \\
15 & 15.0 & 13.1 & 10.6 & 11.8 & $*$ & $*$ & 15.9 & 18.2 & 19.3 & 19.8 & 16.9 \\
20 & 14.8 & 13.1 & 10.6 & 11.7 & $*$ & $*$ & 15.6 & 17.9 & 18.4 & 19.6 & 16.6 \\
25 & 14.7 & 13.1 & 10.6 & 11.6 & $*$ & $*$ & 15.4 & 17.5 & 14.3 & 19.3 & 16.1 \\
30 & - & - & - & - & - & - & - & - & 14.0 & 18.1 & - \\
35 & - & - & - & - & - & - & - & - & 13.4 & 16.7 & - \\
40 & - & - & - & - & - & - & - & - & 12.8 & 15.6 & - \\
\hline
\end{tabular}

*, water temperature not measured; -, no data. 
were $86.3 \pm 12.40 \mathrm{~cm}$ at $5 \mathrm{~m}, 68.7 \pm 15.2 \mathrm{~cm}$ at $10 \mathrm{~m}$, and $59.1 \pm 13.9 \mathrm{~cm}$ at $15 \mathrm{~m}$, demonstrating that growth rates decreased as the culture depth increased.

S. sculpera grown at fixed depths throughout the 10-month culture period showed biomass loss beginning in July at 5-m depth, and in September at 10- and 15-m depths. The blade lengths of the experimental groups in which the rearing depth was adjusted (from $5 \rightarrow 15 \rightarrow 25$ $\mathrm{m} ; 10 \rightarrow 15 \rightarrow 25 \mathrm{~m}$; and $15 \rightarrow 25 \mathrm{~m}$ ) were $64.2 \pm 15.2$, $56.1 \pm 13.7$, and $40.8 \pm 11.4 \mathrm{~cm}$, respectively in October. Mature sporophytes (indicated by presence of sori in the blades) were likewise observed in October for these experimental groups (Table 3).

\section{DISCUSSION}

The growth and maturity of algae can be affected by a variety of environmental conditions such as water temperature, light intensity, nutrients, and competition (Lüning 1990, Augyte et al. 2019), but water temperature and light intensity are considered to be the most important limiting factors (Druehl et al. 1987, Vásquez and Vega, 2001). Kain and Norton (1990) emphasize the importance of temperature, noting that the same species in different water temperatures can vary in terms of both growth rates and maturity. In this study, the juvenile Saccharina sculpera showed high growth at a low temperature $\left(5^{\circ} \mathrm{C}\right)$ and high light intensity $\left(40 \mu \mathrm{mol}\right.$ photons $\left.\mathrm{m}^{-2} \mathrm{~s}^{-1}\right)$ environment, and yet also demonstrated high growth at higher water temperatures $\left(10\right.$ to $\left.15^{\circ} \mathrm{C}\right)$ but at low light intensity $\left(20 \mu \mathrm{mol}\right.$ photons $\left.\mathrm{m}^{-2} \mathrm{~s}^{-1}\right)$. Growth was suppressed under high temperature and high light intensity environment. Sato et al. (2020) reported that the minimum saturated irradiance of S. sculpera increased from 72.6 to $125.7 \mu \mathrm{mol}$ photons $\mathrm{m}^{-2} \mathrm{~s}^{-1}$ when the temperature rose from 8 to $22^{\circ} \mathrm{C}$, indicating that light requirements for growth vary with temperature and therefore could be considered to vary seasonally in the wild. Natural populations of S. sculpera generally occur 13 to $18 \mathrm{~m}$ deeper than S. japonica (Tani et al. 2015). This distribution of S. sculpera was considered to be because it has a higher affinity for low light intensity environments, and that the plant may be subject to photoinhibition at higher light intensities (Sato et al. 2020). In this study, S. sculpera showed the fastest growth at $5 \mathrm{~m}$ depth, where the light intensity was higher than at greater depths. This suggests that photoinhibition did not occur under the higher light intensity. It seems more likely that S. sculpera occurs mainly in deeper waters not because it is adapted to low light intensities, but because the vertical distribution is limited at shallow depths by high water temperatures in summer.

The vertical distribution of water temperature in temperate zones such as Korea is known to have seasonal variation (Sumich and Morrissey 2004). At the cultivation area used in this study, the water temperatures between 1 and $25 \mathrm{~m}$ were relatively stable from December to March (winter season), while a thermocline was observed at shallow depths $(10 \mathrm{~m})$ in June (early summer season) and at deeper depths $(25 \mathrm{~m})$ in August (Table 2). Jeong et al. (2013) reported that in the East Sea coast of Korea, the water temperature-depth profile is uniform in winter as seasonal winds induce vertical mixing. In summer, a thermocline starts to develop due to the warming of the sea surface, which becomes strongest in August. In autumn, the mixed layer becomes deeper due to cooling on the sea surface. These patterns align well with the vertical distribution pattern of the water temperature observed in this study.

Tani et al. (2015) reported that, for the S. sculpera population off the coast of Hakodate, Japan, the recruitment of new thalli occurs from January to June, when the average monthly water temperature ranges between 5 and $15^{\circ} \mathrm{C}$. Kirihara et al. (2003) and National Institute of Fisheries Science (2020) also reported that the juvenile S. sculpera in indoor culture only grew at water temperatures between 5 and $15^{\circ} \mathrm{C}$. However, these two studies could not draw conclusions about the critical temperature for sur-

Table 3. Monthly maturation of Saccharina sculpera sporophytes (sorus formation) according to transplant depth

\begin{tabular}{|c|c|c|c|c|c|c|c|c|c|c|}
\hline Depth control (m) & Jan & Feb & Mar & Apr & May & Jun & Jul & Aug & Sep & Oct \\
\hline 5 & - & - & - & - & - & - & - & $*$ & $*$ & $*$ \\
\hline $5 \rightarrow 15 \rightarrow 25$ & - & - & - & - & - & - & - & - & - & + \\
\hline 10 & - & - & - & - & - & - & - & - & * & $*$ \\
\hline $10 \rightarrow 15 \rightarrow 25$ & - & - & - & - & - & - & - & - & - & + \\
\hline 15 & - & - & - & - & - & - & - & - & * & $*$ \\
\hline $15 \rightarrow 25$ & - & - & - & - & - & - & - & - & - & + \\
\hline
\end{tabular}

- , sterile; + , formation of sorus; ${ }^{*}$, death. 


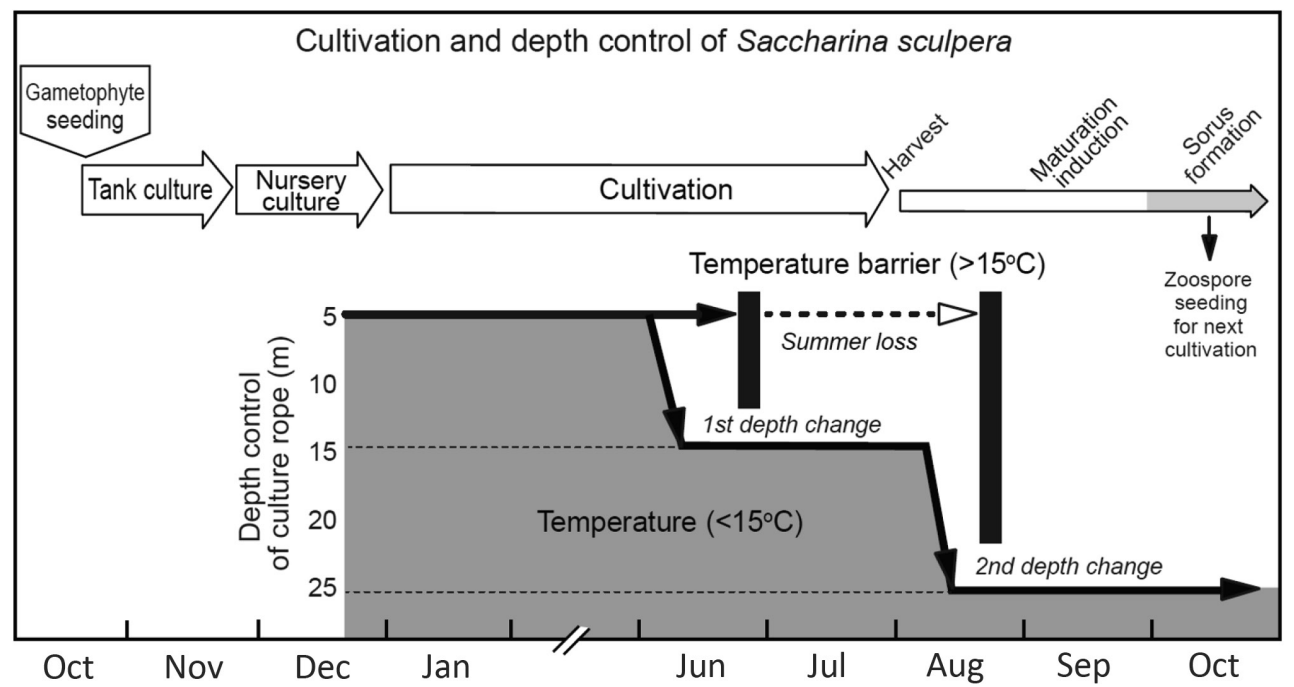

Fig. 8. Diagram of cultivation and depth adjustments of Saccharina sculpera to allow maturation, in situ, for the next cultivation. Seawater temperatures reached critical levels (over $16^{\circ} \mathrm{C}$ ) at $10 \mathrm{~m}$ depth in June, and up to $20 \mathrm{~m}$ depth in August. To allow maximum growth and maturation of this alga, it is necessary to adjust the culture depths appropriately.

vival of the juvenile stage as the experiments were conducted at $5^{\circ} \mathrm{C}$ water temperature intervals. This present study identified the maximum water temperature for the survival of the juvenile S. sculpera as $16^{\circ} \mathrm{C}$, and normal growth occurred at temperatures below $15^{\circ} \mathrm{C}$.

The natural S. sculpera population in Japan mainly occurs at 13-18 m depth (Tani et al. 2015), while the population in Sageunjin coast of Gangneung, Korea occurs at 20-30 m depth (Kim et al. 2005, 2007b). Kelp population described in Tani et al. (2015) had newly recruited thalli from January to July (year 1 cohort), and their blade lengths reached around $10 \mathrm{~cm}$ by October without maturing (Tani et al. 2015). S. sculpera has been reported to grow up to $2 \mathrm{~m}$ or more in length in June-July of the following year, indicating that the commercially utilized individuals have grown for more than two years. In this study, S. sculpera showed maximum growth at $5 \mathrm{~m}$ depth (86.3 $\pm 12.4 \mathrm{~cm}$ in June), with declining blade length as culture depth increased. This was similar to the study by Kim et al. (2007b), which reported that the optimum water depth was $5 \mathrm{~m}$ for the growth of $S$. sculpera and the lowest growth was observed at $30 \mathrm{~m}$ depth. However, loss of sporophyte biomass was observed at $5 \mathrm{~m}$ depth during summer in this study, as seawater temperatures reach $19-20^{\circ} \mathrm{C}$. This suggests the negative impact of high seawater temperature on the physiological condition of the seaweed.

In order to maintain kelp cultivars below their lethal temperature in the field, the rearing depth was lowered from 5 to $15 \mathrm{~m}$ in June. This resulted in individuals reach- ing a market size of $90 \mathrm{~cm}$ or more in July. The Ministry of Fisheries, Korea (2007) reported that blade lengths of $S$. sculpera in the wild grown for more than two years were in the range of 87.5 to $132.5 \mathrm{~cm}$, which was similar to the size of the first-year S. sculpera in this study.

In August, the rearing depth was further adjusted from 15 to $25 \mathrm{~m}$, which resulted in the maturation of adult sporophytes in October. Azevedo et al. (2019) reported that the growth of S. latissima was fastest at $5 \mathrm{~m}$ depth and decreased as the water depth increased, which is consistent with the results of this study. They also inferred that the effect of high temperature at deep water would decrease due to the rapid formation of thermocline in May. Results of our study are consistent with theirs, and thereby suggest that the growth period can be extended by adjusting the culture depth according to the summer thermocline. This technique could contribute to the increase in S. sculpera production or yield, and provide a sustainable source of parental sporophytes for the mass production of seedlings (Fig. 8). The availability of mature sporophytes of $S$. sculpera provides opportunities for both habitat restoration and aquaculture. However, if habitat restoration is pursued without aquaculture, the large-scale harvest of the species may damage natural habitats, risking another localized extinction (Kim 2003, Kim et al. 2005). It is expected that the results of this study can be utilized to secure the sustainable supply of S. sculpera biomass through cultivation without causing damage to natural S. sculpera resources. 


\section{ACKNOWLEDGEMENTS}

The study was funded by the National Institute of Fisheries Science in 2021 (R2021005). The authors would like to thank Dr. Philip Heath (Tisbe Ltd., New Zealand) for reviewing the English.

\section{CONFLICTS OF INTEREST}

The authors declare that they have no potential conflicts of interest.

\section{REFERENCES}

Augyte, S., Yarish, C. \& Neefus, C. D. 2019. Thermal and light impacts on the early growth stages of the kelp Saccharina angustissima (Laminariales, Phaeophyceae). Algae 34:153-162.

Azevedo, I. C., Duarte, P. M., Marinho, G. S., Neumann, F. \& Sousa-Pinto, I. 2019. Growth of Saccharina latissima (Laminariales, Phaeophyceae) cultivated offshore under exposed conditions. Phycologia 58:504-515.

Boo, S. M., Lee, W. J., Hwang, I. K., Keum, Y. S., Oak, J. H. \& Cho, G. Y. 2010. Algal flora of Korea. Vol. 2, No. 2, Marine brown algae II. National Institute of Biological Resources, Ministry of Environment, Incheon, 203 pp.

Breeman, A. M. 1988. Relative importance of temperature and other factors in determining geographic boundaries of seaweeds: experimental and phenological evidence. Helgol. Meeresunters. 42:199-241.

Druehl, L. D., Cabot, E. L. \& Lloyd, K. E. 1987. Seasonal growth of Laminaria groenlandica as a function of plant age. Can. J. Bot. 65:1599-1604.

Galanin, D., Yotsukura, N. \& Kawai, T. 2011. Distributional information of Saccharina sculpera in Japan and Saghalin, Russia. Algal Resour. 4:1-7 (in Japanese with English abstract).

Hwang, E. K. \& Park, C. S. 2020. Seaweed cultivation and utilization of Korea. Algae 35:107-121.

Hwang, E. K., Yoo, H. C., Kim, S. M., Beak, J. M. \& Park, C. S. 2015. Isolation, regeneration and maturation induction of free-living gametophytes of Saccharina japonica (Phaeophyceae). Korean J. Environ. Biol. 33:248-255.

Jeong, H. -D., Kim, S. -W., Kwon, K. -Y., Lim, J. -W. \& Kwoun, C. -H. 2013. Oceanographic features around aquaculture areas of the eastern cost of Korea. J. Korean Soc. Mar. Environ. Saf. 19:334-344.

Kain, J. M. \& Norton, T. A. 1990. Marine ecology. In Cole, K.
M. \& Sheath, R. G. (Eds.) Biology of the Red Algae. Cambridge University Press, Cambridge, pp. 377-422.

Kang, J. W. 1968. Illustrated encyclopedia of fauna and flora of Korea. Vol. 8. Marine algae. Ministry of Education, Seoul, $465 \mathrm{pp}$.

Katayama, S., Nishio, T., Iseya, Z., Kishimura, H. \& Saeki, H. 2009. Effects of manufacturing factors on the viscosity of a polysaccharide solution extracted from Gagome Kjellmaniella crassifolia. Fish. Sci. 75:491-497.

Kim, H. G. 2003. Environmental adaptation of native kelp Kjellmaniella crassifolia and marine environment in Gangwon coast. In Proc. 6th Korea-Japan Fish. Semin., Korea Science and Engineering Foundation, Seoul and Japan Society for the Promotion of Science, Tokyo, pp. 25-37.

Kim, H. G., Park, J. G. \& Kim, D. S. 2005. Comparative laboratory culture studies of the native kelp Kjellmaniella crassifolia and the introduced kelp Laminaria japonica in east coast of Korea. J. Aquac. 18:299-304.

Kim, J. -H., Kim, Y. -D., Song, H. -I., Gong, Y. -G., Lee, S. -B. \& Jin, H. -J. 2007a. Separation and preservation of the male and female gametophytes of Kjellmaniella crassifolia Miyabe (Phaeophyta). J. Korean Fish. Soc. 40:387-393.

Kim, Y. -D., Song, H. -I., Kim, J. -H., Hong, J. -P., Jeon, C. -Y., Han, H. -K., Kim, S. -K., Kim, D. -S., Kim, M. -R. \& Jin, H. -J. 2007b. Study of the early life of Kjellmaniella crassifolia and its growth in the eastern coast of the Korean Peninsula. J. Korean Fish. Soc. 40:315-322.

Kirihara, S., Fujikawa, Y. \& Notoya, M. 2003. Effect of the temperature and light intensity on the growth of zoospore germling of Kjellmaniella crassifolia Miyabe (Laminariales, Phaeophyceae) in culture. Aquac. Sci. 51:281-286 (in Japanese with English abstract).

Ko, S. J., Kim, Y. K., Hong, S. W., Kang, M. S., Park, C. S., Hwang, E. K. \& Lee, Y. D. 2020. Artificial seed production and cultivation of Sargassum macrocarpum (Fucales, Phaeophyta). Algae 35:123-131.

Leandro, A., Pereira, L. \& Gonçalves, A. M. M. 2020. Diverse applications of marine macroalgae. Mar. Drugs 18:17.

Lee, I. K. \& Kim, Y. H. 1999. Biodiversity and distribution of marine benthic organisms and uses of algal resources in the coastal zone of Korea and Japan. I. Benthic marine algae in the east coast of Korea. Algae 14:91-110.

Lüning, K. 1990. Seaweeds: their environment, biogeography, and ecophysiology. Wiley, New York, 527 pp.

Lüning, K. 1993. Environmental and internal control of seasonal growth in seaweeds. Hydrobiologia 260/261:1-14.

Minisrty of Oceans and Fisheries. 2007. Studies on Kjellmaniella crassifolia for wildstock restoration and industrialized aquaculture. Minisrty of Oceans and Fisheries, 
Sejong, $132 \mathrm{pp}$.

National Institute of Fisheries Science. 2020. Technical report of National Institute of Fisheries Science. National Institute of Fisheries Science, Busan, 819 pp.

Notoya, M. \& Kim, H. G. 1996. Influence of light intensity and temperature on callus cell propagation and differentiation to bladelets from the explants of young sporophyte of Kjellmaniella crassifolia Miyabe (Phaeophyta, Laminariales). Algae 11:179-182.

Ozaki, A., Mizuta, H. \& Yamamoto, H. 2001. Physiological differences between the nutrient uptakes of Kjellmaniella crassifolia and Laminaria japonica (Phaeophyceae). Fish. Sci. 67:415-419.

Qu, T., Cao, Z., Wang, W., Wang, N., Li, X. \& Pan, J. 2019. Monthly variations of fucoidan content and its composition in the farmed brown alga Saccharina sculpera (Laminariales, Phaeophyceae). J. Appl. Phycol. 31:26232628.

Ren, D., Wang, Q., Yang, Y., Hu, Y., Song, Y., He, Y., Liu, S. \& Wu, L. 2019. Hypolipidemic effects of fucoidan fractions from Saccharina sculpera (Laminariales, Phaeophyceae). Int. J. Biol. Macromol. 140:188-195.

Sakai, T. \& Kato, I. 2001. Functionality of kelp fucoidan and its use in health foods. New Food Ind. 43:8-12 (in Japanese).

Sakai, T. \& Kato, I. 2002. Structure and biological activity of seaweed-derived fucoidan and its oligosaccharides. Biosci. Ind. 60:23-26 (in Japanese).

Sasaki, S., Kawashima, S. \& Kadoma, H. 1992. Natural kelp failure Research of cause. Life and marine environment survey report of kelp in Toi area Declaration. Toi Town, $89 \mathrm{pp}$.

Sato, Y., Kozono, J., Nishihara, G. N. \& Terada, R. 2020. Effect of light and temperature on photosynthesis of a cultivated brown alga, Saccharina sculpera (Laminariales), from Japan. Phycologia 59:375-384.

Serisawa, Y., Yokohama, Y., Aruga, Y. \& Tanaka, J. 2002. Growth of Ecklonia cava (Laminariales, Phaeophyta) sporophytes transplanted to a locality with different temperature conditions. Phycol. Res. 50:201-207.

South, G. R. \& Whittick, A. 1987. Introduction to phycology. Blackwell Scientific Publications, Oxford, 341 pp.

Sumich, J. L. \& Morrissey, J. F. 2004. Introduction to the biology of marine life. 8th ed. Jones and Bartlett Publishhers, Sudbury, MA, 431 pp.

Takahashi, K. 2000. Changes in the growth of gagome in the Oshima area. Kitasui Mag. 49:22.

Tani, T., Kawagoe, C., Matsumoto, S., Mizuta, H. \& Yasui, H. 2015. Seasonal variations and morphological changes of sporophytes of Saccharina sculpera (Laminariales, Phaeophyceae) from Hakodate, Hokkaido. Aquac. Sci. 63:235-244.

Tatewaki, M. 1966. Formation of a crustose sporophyte with unilocular sporangia in Scytosiphon lomentaria. Phycologia 6:62-66.

Vásquez, J. A. \& Vega, J. M. A. 2001. Chondracanthus chamissoi (Rhodophyta, Gigartinales) in northern Chile: ecological aspects for management of wild populations. J. Appl. Phycol. 13:267-277.

Yamamoto, H. 1986. Monthly changes in the occurrence and growth of Kjellmaniella crassifolia Miyabe. Bull. Fac. Fish. Hokkaido Univ. 37:165-170.

Yoo, H. I., Lee, K. H., Kim, S. H., Ha, D. S. \& Hwang, E. K. 2018. Regeneration and the maturation induction of free-living gametophytes of a kelp Saccharina sculpera (Phaeophyceae). Korean J. Environ. Biol. 36:576-583. 